\title{
Gestational diabetes and the risk of cardiovascular disease in women: a systematic review and meta-analysis
}

\author{
Caroline K. Kramer ${ }^{1,2,3} \cdot$ Sara Campbell $^{1} \cdot$ Ravi Retnakaran $^{1,2,3}$ (D) \\ Received: 16 October 2018 / Accepted: 4 February 2019 / Published online: 7 March 2019 \\ (C) Springer-Verlag GmbH Germany, part of Springer Nature 2019
}

\begin{abstract}
Aims/hypothesis Women who develop gestational diabetes mellitus (GDM) have an elevated lifetime risk of type 2 diabetes mellitus. Recently, a series of studies has suggested that women with GDM also have an increased risk of cardiovascular disease (CVD). However, it is unclear if this risk is dependent upon the intercurrent development of type 2 diabetes. Thus, we conducted a systematic review and meta-analysis to evaluate the impact of GDM on future risk of incident CVD and to ascertain the role of type 2 diabetes in this regard.

Methods We systematically searched the PubMed and EMBASE databases for observational studies that evaluated the association of GDM with subsequent CVD, with publication between 1 January 1950 and 30 August 2018. Two independent reviewers extracted data and the analysis was performed in accordance with Meta-analysis of Observational Studies in Epidemiology (MOOSE) guidelines. RRs were calculated using a random-effects model to assess the predictive value of GDM for future cardiovascular events. To evaluate whether incident type 2 diabetes in the GDM population influenced the association with CVD, we used meta-regression models followed by sensitivity analyses restricted to women who did not develop type 2 diabetes during follow-up.

Results A pooled analysis of nine studies yielded data from 5,390,591 women (101,424 cardiovascular events). Compared with those who did not have GDM, women with GDM had a twofold higher risk of future cardiovascular events (RR 1.98 [95\% CI $1.57,2.50])$. Meta-regression analysis showed that the rates of incident type 2 diabetes across the studies did not affect this risk $(p=0.34)$. Moreover, when restricted to women who did not develop type 2 diabetes, GDM remained associated with a 56\% higher risk of future cardiovascular events (RR 1.56 [95\% CI 1.04, 2.32]). GDM conferred a 2.3-fold increased risk of cardiovascular events in the first decade postpartum (RR 2.31 [95\% CI 1.57, 3.39]).

Conclusions/interpretation The diagnosis of GDM identifies young women who have a twofold higher risk of cardiovascular events postpartum compared with their peers. This risk is not dependent upon intercurrent type 2 diabetes and is apparent within the first decade after pregnancy. Thus, even without progressing to type 2 diabetes, women with GDM comprise an at-risk population for CVD and hence a potential opportunity for early risk factor surveillance and risk modification.
\end{abstract}

Keywords Cardiovascular disease · Gestational diabetes · Meta-analysis · Risk factors · Systematic review · Type 2 diabetes . Women's health

Caroline K. Kramer and Sara Campbell contributed equally to this work.

Electronic supplementary material The online version of this article (https://doi.org/10.1007/s00125-019-4840-2) contains peer-reviewed but unedited supplementary material, which is available to authorised users.

Ravi Retnakaran

Ravi.Retnakaran@sinaihealthsystem.ca

1 Leadership Sinai Centre for Diabetes, Mount Sinai Hospital, 60 Murray Street, Suite L5-025, Mailbox-21, Toronto, ON M5T 3L9, Canada
2 Division of Endocrinology, University of Toronto, Toronto, ON, Canada

3 Lunenfeld-Tanenbaum Research Institute, Mount Sinai Hospital, Toronto, ON, Canada 


\section{Research in context}

\section{What is already known about this subject?}

- Women who develop gestational diabetes mellitus (GDM) have an elevated risk of type 2 diabetes in the years thereafter

- A series of recent studies has suggested that women with GDM also have an increased future risk of cardiovascular disease (CVD)

- However, these studies have yielded varying estimates of the magnitude of risk and offered conflicting evidence on whether this risk is dependent upon the development of type 2 diabetes

\section{What is the key question?}

- What is the magnitude of future CVD risk in women with previous GDM, and is this risk dependent upon the intercurrent development of type 2 diabetes?

\section{What are the new findings?}

- This meta-analysis, involving more than five million women, demonstrates that women with GDM have a twofold higher risk of major cardiovascular events than their peers

- This increased risk is not dependent upon intercurrent type 2 diabetes

- The risk differential emerges within the first decade after pregnancy

\section{How might this impact on clinical practice in the foreseeable future?}

- With or without subsequent type 2 diabetes, the diagnosis of GDM should be recognised as identifying future risk of CVD and hence as an opportunity for early risk modification and possibly prevention of the leading cause of mortality in women

\section{Abbreviations \\ CVD Cardiovascular disease \\ GDM Gestational diabetes mellitus \\ NOS Newcastle-Ottawa scale}

\section{Introduction}

Gestational diabetes mellitus (GDM), or glucose intolerance with first onset and recognition in pregnancy, has been a clinical entity fraught with controversy since its first description in 1964 [1]. While ongoing debate in the ensuing half-century has centred around the diagnostic criteria and the optimal protocol for its screening and detection, there is universal recognition that GDM identifies future risk of type 2 diabetes [2]. Indeed, although glucose tolerance typically returns to normal in the immediate postpartum period, women with GDM have a $20-70 \%$ risk of progressing to type 2 diabetes in the first decade after delivery [2]. Thus, GDM is an established clinical predictor of future diabetes risk, with affected women exhibiting a greater than sevenfold higher overall incidence of type 2 diabetes, as compared with their peers [2].

Whereas the association between hyperglycaemia in pregnancy and subsequent type 2 diabetes has been known for more than 50 years, a much more recent development has been recognition of an analogous relationship with cardiovascular disease (CVD). Notably, a series of studies in recent years has suggested that, despite their relative youth (i.e. being of childbearing age), women with GDM have an increased incidence of major cardiovascular events in the years to decades postpartum [3]. However, these studies have yielded varying estimates of the magnitude of this risk, and have offered conflicting evidence on whether it is dependent upon the intercurrent development of type 2 diabetes. Specifically, whereas some studies have suggested that women with GDM only develop CVD if they progress to type 2 diabetes [4-6], others have argued that an increased cardiovascular risk can manifest even in the absence of diabetes [7-9].

This conflicting evidence holds fundamental implications for clinical cardiovascular risk assessment in women. Namely, if an increased cardiovascular risk only manifests upon progression to type 2 diabetes, then clinical monitoring of glucose tolerance should suffice for prompting vascular evaluation in women with a history of GDM. Conversely, if this risk is not dependent upon intercurrent type 2 diabetes, then all women with GDM may warrant vascular surveillance in practice, regardless of whether they develop diabetes. Thus, in this context, we performed a systematic review and meta-analysis to: (1) obtain robust quantification of the future risk of CVD in women with GDM; and (2) ascertain the role of type 2 diabetes in this regard. 


\section{Methods}

This systematic review and meta-analysis is reported in accordance with the Meta-analysis of Observational Studies in Epidemiology (MOOSE) guidelines and was registered at the International Prospective Register of Systematic Reviews (http://www.crd.york.ac.uk/prospero; CRD42018096478) [10].

Search strategy and selection criteria To perform a systematic review of the published literature, we selected relevant studies published between 1 January 1950 and 30 August 2018 by searching EMBASE and PubMed. We used the combined medical subject headings (MeSH) terms 'Diabetes, Gestational' and 'Cardiovascular'. The complete search used for PubMed was 'Diabetes, Gestational' $[\mathrm{MeSH}]$ and ('Cardiovascular Diseases' [MeSH] OR 'Cardiovascular' [text]). All potentially eligible studies were considered for review, regardless of the primary outcome or language. A manual search was also performed, using the references of key articles published in English.

Studies were considered eligible for inclusion if they were observational studies of women with and without GDM, and reported the number of participants with any cardiovascular event in each arm. Cardiovascular events included fatal and non-fatal ischaemic heart disease and cerebrovascular events. Studies were excluded if the cardiovascular outcome was self-reported or if only surrogate cardiovascular markers were reported.

Data extraction and quality assessment Two independent investigators (C. K. Kramer and S. Campbell) reviewed the study titles and abstracts, and studies that satisfied the inclusion criteria were retrieved for full-text evaluation. Studies selected for detailed analysis and data extraction were analysed by the two investigators with an agreement value (K) of $97.5 \%$; disagreements were resolved by a third investigator (R. Retnakaran). The following data were extracted from each selected study: total number of participants; number of participants with previous GDM; mean participant age; study duration; incidence of type 2 diabetes in the GDM population; and number of participants with any cardiovascular event in women with and without previous GDM. We emailed the authors of the included studies to obtain missing descriptive data and data on cardiovascular events in women who did not develop type 2 diabetes. When studies only reported individual rates of cardiovascular events, we used combined estimates for pooling the data.

The Newcastle-Ottawa scale (NOS) for assessing the quality of observational studies in meta-analysis was applied (see Electronic Supplementary Material [ESM] Table 1) [11]. The NOS contains eight items, categorised into three domains of selection, comparability and exposure. For each item, a series of response options is provided. A star system is used to enable semi-quantitative assessment of study quality, with the highest-quality studies awarded a maximum of one star for each item with the exception of the comparability domain, which allows the assignment of two stars. As such, the NOS ranges between zero and nine stars [12].

Data synthesis and analysis An overall RR was calculated to assess the predictive value of GDM for future cardiovascular events. We calculated pooled estimates of the RR using a random-effects model (DerSimonian-Laird method) to adequately account for the additional uncertainty associated with study-study variability. The Cochran $Q$ test was used to evaluate heterogeneity among studies, with a threshold of $p<0.1$ considered statistically significant. $I^{2}$ testing was also performed to evaluate heterogeneity among studies, with values above $50 \%$ considered indicative of high heterogeneity [13].

We explored heterogeneity among studies using three strategies. First, we re-ran the meta-analysis removing each study one at a time to determine whether a particular study accounted for the heterogeneity. Second, we performed sensitivity analyses to assess subgroups of studies most likely to yield valid estimates of the intervention based on clinically relevant study characteristics, such as duration of follow-up, mean age and incidence of type 2 diabetes. Finally, recognising that random-effect models attribute increased weight to small studies in determining an overall estimate, we performed sensitivity analyses including only the three largest studies. We also performed a sensitivity analysis pooling adjusted data from the studies to address the possibility of confounding.

Publication bias was assessed using a funnel plot of effect size against standard error for every study. Funnel plot asymmetry was tested using Begg and Egger tests, with significant publication bias defined by $p<0.1$ [14].

To evaluate the potential confounder effect of incident type 2 diabetes in the association between GDM and subsequent cardiovascular events, two approaches were used. First, using randomeffects univariate meta-regression models, we assessed whether the incident rates of type 2 diabetes in the GDM population of each study influenced the association of GDM and CVD. Second, we performed sensitivity analyses that were restricted to only those women who did not develop type 2 diabetes.

Finally, to evaluate the impact of GDM on the risk of CVD over time, meta-regression was performed to evaluate whether the duration of follow-up in the study impacted the estimate of CVD risk associated with GDM. We also performed sensitivity analyses restricted to only those studies with $\leq 10$ years of follow-up after the index pregnancy. All analyses were performed using Stata 11.0 (Stata, College Station, TX, USA).

\section{Results}

We identified 1737 studies through electronic searches and one study using a manual search. Of these, 1723 were excluded on the basis of the title and abstract, leaving 15 studies for 
further assessment (ESM Fig. 1). Six studies were excluded after full assessment; four did not meet our criteria for the outcome and two had study populations that overlapped with those of an included study (ESM Fig. 1). Nine studies met our inclusion criteria $[6,8,9,15-20]$ and were included in the analysis, providing data on 5,390,591 women and 101,424 cardiovascular events (8003 in women with GDM and 93,421 in women without GDM). Table 1 summarises the included studies, which were all published between 2013 and 2018. One study had a case-control design [16], while the others were cohort studies. The studies varied in their sample size, ranging from fewer than 100,000 women [6, $15,16,19]$ to $200,000-900,000[17,18]$ and more than one million women $[8,9,20]$. The mean duration of follow-up varied from 1.0 to 25.7 years. Evaluation of the quality of the studies is shown in ESM Table 1. In accordance with the NOS quality assessment scale for cohort studies, the majority of studies achieved at least seven stars, indicative of overall good quality.

In the main analyses ( $n=5,390,591$ women), compared with those without a history of GDM, the RR for future cardiovascular events in women with previous GDM was 1.98 (95\% CI 1.57, 2.50) (Fig. 1). All but one study reported a significantly higher risk of cardiovascular events in women with GDM. However, there was significant heterogeneity in the individual estimates of the magnitude of the association $\left(I^{2}=98.6 \%, p<0.001\right)$. There was no evidence of publication bias on the Egger regression test ( $p=0.25$ ) (ESM Fig. 2). The effect of GDM on CVD risk was largest in the studies by Savitz et al [17] and Kessous et al [15], potentially reflecting the limited duration of follow-up in the former (1 year postpartum) and differences in the participant population of the latter (i.e. being from a tertiary-care centre). In an attempt to explore the heterogeneity among studies, we re-ran the metaanalysis removing each study one at a time, but found that no particular study accounted for the heterogeneity. In addition, subgroup analyses by duration of follow-up, mean age and incidence of type 2 diabetes also did not account for the heterogeneity (data not shown). Conversely, however, variability in sample sizes appeared to play a role. Indeed, when we performed sensitivity analyses restricted to the three largest studies $[8,9,20]$, which provided data on 4,101,133 women, we confirmed that GDM was associated with an increased risk of cardiovascular events (RR 1.52 [95\% CI 1.48, 1.56]) with non-significant heterogeneity of $2.6 \%(p=0.36)$. Coupled with the robust sample size of the overall analysis and recognition that all but one of the nine studies noted significantly increased cardiovascular risk in women with previous GDM,

Table 1 Characteristics of the included studies

\begin{tabular}{|c|c|c|c|c|c|c|c|c|}
\hline Study & Year & Country & Study type & $\begin{array}{l}\text { Study population } \\
\text { (sample size included } \\
\text { in the analysis) }\end{array}$ & $\begin{array}{l}\text { Women with } \\
\text { GDM, } n(\%)\end{array}$ & $\begin{array}{l}\text { Mean } \\
\text { maternal } \\
\text { age at } \\
\text { pregnancy, } \\
\text { years }\end{array}$ & $\begin{array}{l}\text { Duration } \\
\text { of follow- } \\
\text { up, years }\end{array}$ & $\begin{array}{l}\text { Incidence of type } 2 \\
\text { diabetes in GDM } \\
\text { population, } \%\end{array}$ \\
\hline Kessous et al [15] & 2013 & Israel & $\begin{array}{l}\text { Retrospective } \\
\text { cohort }\end{array}$ & $\begin{array}{l}\text { Women seen at tertiary } \\
\text { centre }(47,909)\end{array}$ & $4928(10.3)$ & 29.7 & 10.0 & $\mathrm{NA}$ \\
\hline Fadl et al [16] & 2014 & Sweden & Case-control & $\begin{array}{l}\text { Data from Swedish national } \\
\quad \text { registry }(15,949)\end{array}$ & $210(1.3)$ & NA & $9.1^{\mathrm{b}}$ & $\mathrm{NA}$ \\
\hline Savitz et al [17] & 2014 & USA & $\begin{array}{l}\text { Retrospective } \\
\text { cohort }\end{array}$ & $\begin{array}{l}\text { Data from the New York City } \\
\text { administrative databases } \\
(849,639)\end{array}$ & $43,169(5.1)$ & 28.0 & 1.0 & 0.3 \\
\hline Kaul et al [18] & 2015 & Canada & $\begin{array}{l}\text { Retrospective } \\
\text { cohort }\end{array}$ & $\begin{array}{l}\text { Data from Alberta provincial } \\
\text { administrative databases } \\
(240,083)\end{array}$ & 8731 (3.6) & 28.8 & 5.3 & 21.6 \\
\hline Goueslard et al [8] & 2016 & France & $\begin{array}{l}\text { Retrospective } \\
\text { cohort }\end{array}$ & $\begin{array}{l}\text { Data from French } \\
\text { administrative } \\
\text { databases }(1,515,387)\end{array}$ & $62,958(4.1)$ & 30.6 & 7.0 & 2.0 \\
\hline Tobias et al [6] & 2017 & USA & $\begin{array}{l}\text { Prospective } \\
\text { cohort }\end{array}$ & $\begin{array}{l}\text { Data from Nurses' Health } \\
\text { Study II }(89,479)\end{array}$ & $5292(5.9)$ & 34.9 & 25.7 & 19.0 \\
\hline $\begin{array}{l}\text { Retnakaran and } \\
\text { Shah [9] }\end{array}$ & 2017 & Canada & $\begin{array}{l}\text { Retrospective } \\
\text { cohort }\end{array}$ & $\begin{array}{l}\text { Data from Ontario provincial } \\
\text { administrative databases } \\
(1,515,079)\end{array}$ & $56,884(3.8)$ & 31.2 & 10.0 & 27.3 \\
\hline Daly et al [19] & 2018 & UK & $\begin{array}{l}\text { Retrospective } \\
\text { cohort }\end{array}$ & $\begin{array}{c}\text { Data from primary-care } \\
\text { database }(46,399)\end{array}$ & 9118 (19.7) & 33.0 & 25.0 & 10.0 \\
\hline $\begin{array}{l}\text { McKenzie-Sampson } \\
\text { et al [20] }\end{array}$ & 2018 & Canada & $\begin{array}{l}\text { Retrospective } \\
\text { cohort }\end{array}$ & $\begin{array}{l}\text { Data from Quebec provincial } \\
\quad \text { registry }(1,070,667)\end{array}$ & $67,356(6.3)$ & NA & 25.0 & 3.7 \\
\hline
\end{tabular}

${ }^{a}$ Duration is given either as mean or median, as reported in each study

${ }^{\mathrm{b}}$ Mean time from pregnancy to outcome

NA, data not available 


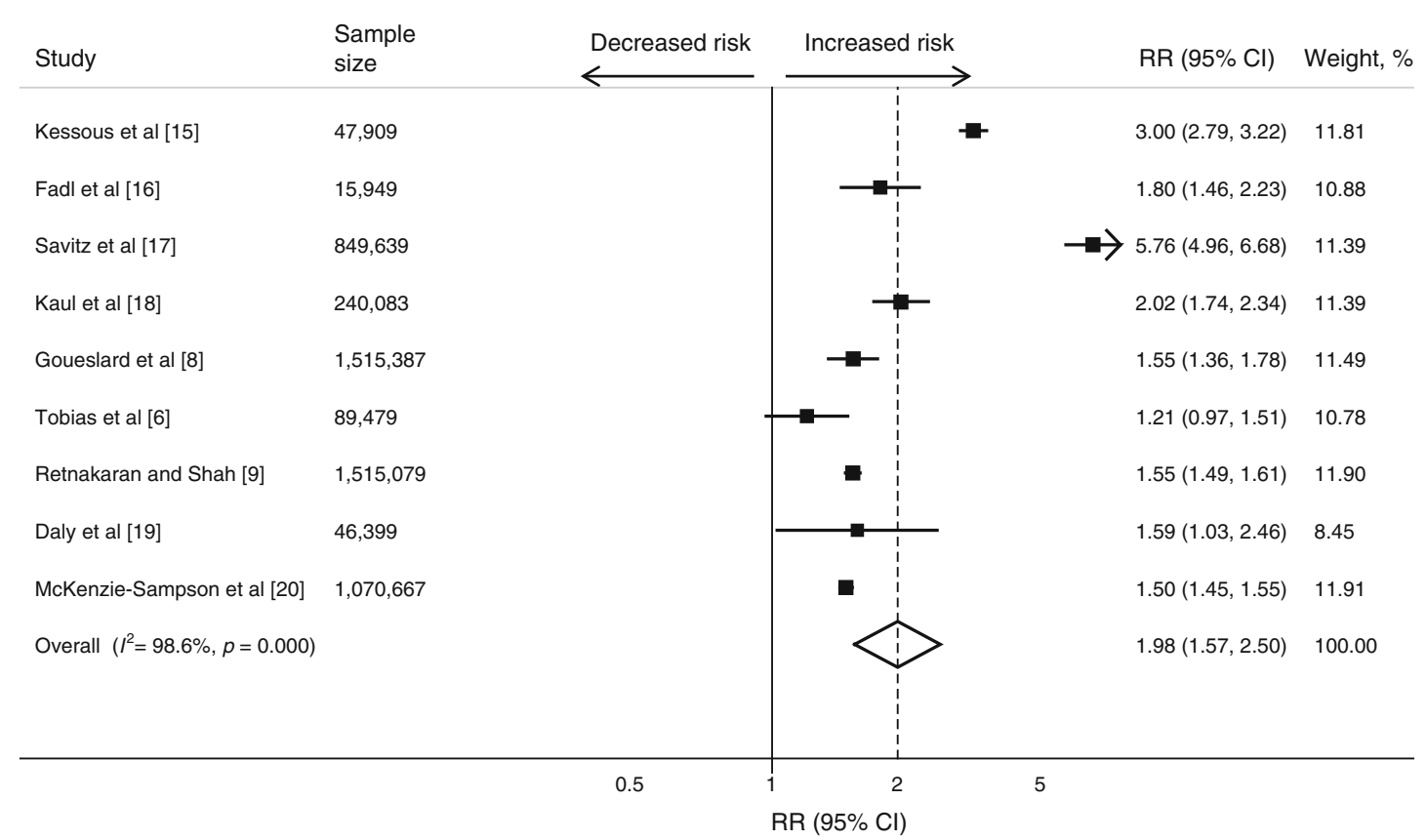

Fig. 1 Meta-analysis of the association between GDM and the risk of cardiovascular events. Weights are from random-effects analysis

these data are reassuring of the reliability of the observed relationship between GDM and subsequent CVD.

To address the possibility of confounding, we performed a sensitivity analysis in which we pooled the adjusted data from each study. While each study provided at least one adjusted model, the potential confounders for which the estimates were adjusted varied among the studies. In addition, some studies presented these data stratified by outcome or by clinical characteristics such as obesity or subsequent progression to diabetes. These study-specific features of the adjusted analyses are shown in Table 2. To pool these adjusted data, we used a random-effects model in which we included the adjusted HR of the most comprehensive adjusted model reported in each study. When these data were provided by specific CVD outcome or by specific clinical characteristics, we included the data from the most prevalent CVD outcome or from the largest clinical group. On this sensitivity analysis, GDM remained independently associated with future CVD (HR 1.59 [95\% CI $1.35,1.85], I^{2}=86.3 \%$ ).

Impact of incident type $\mathbf{2}$ diabetes To address the potential impact of incident type 2 diabetes on the risk of CVD conferred by GDM, we performed univariate meta-regression analysis to assess whether the rate of type 2 diabetes in each individual study impacted the association between GDM and cardiovascular events. This analysis revealed that the rates of incident type 2 diabetes across the studies did not affect the risk conferred by GDM ( $p=0.34)$ (ESM Fig. 3). Consistent with these results, sensitivity analyses restricted to only those women who did not develop type 2 diabetes during follow-up demonstrated that, even in the absence of type 2 diabetes,
GDM is associated with $56 \%$ higher risk for future cardiovascular events (RR 1.56 [95\% CI 1.04, 2.32]) (Fig. 2).

Impact of GDM on risk of CVD over time Finally, we sought to evaluate the impact of GDM on the risk of CVD over time in affected women. Meta-regression analysis of the impact of duration of follow-up suggested that the differential risk of CVD between women with GDM and those without GDM was highest in the first decade after the index pregnancy and decreased over time $(p=0.06)$ (ESM Fig. 4$)$. We thus performed a sensitivity analysis restricted to studies with a follow-up duration of $\leq 10$ years. This analysis revealed that GDM was indeed associated with a 2.3-fold increase in cardiovascular events in the first decade postpartum (RR 2.31 [95\% CI 1.57, 3.39]) (Fig. 3). It thus emerges that the diagnosis of GDM identifies a population of women who are at risk for CVD at a time in life (i.e. during their reproductive years) when their peers are not; a differential risk that may be attenuated over time as the latter reach middle/older age and beyond, when the overall incidence of CVD in women is known to rise.

\section{Discussion}

In this meta-analysis involving more than five million women, we have demonstrated three key findings. First, compared with their peers, women with GDM have a twofold higher risk of major cardiovascular events in the years after the index pregnancy. Second, this risk is not dependent upon the intercurrent development of type 2 diabetes. Third, despite their relative 
Table 2 Description of basis of GDM diagnosis and definition of CVD outcome in the included studies

\begin{tabular}{|c|c|c|c|}
\hline Study & Year & Basis of GDM diagnosis & Definition of CVD \\
\hline Kessous et al [15] & 2013 & $\begin{array}{l}\text { Two-step: } 50 \mathrm{~g} \text { glucose challenge followed by } 3 \mathrm{~h} \\
100 \mathrm{~g} \text { glucose challenge }\end{array}$ & $\begin{array}{l}\text { Hospitalisation for any cardiovascular basis; complex } \\
\text { cardiovascular events; myocardial infarction and simple } \\
\text { cardiovascular events; angina pectoris and CHF, invasive } \\
\text { cardiovascular events; percutaneous coronary } \\
\text { intervention }\end{array}$ \\
\hline Fadl et al [16] & 2014 & $\begin{array}{l}75 \text { g glucose challenge: fasting capillary whole blood } \\
\text { glucose } \geq 6.1 \mathrm{mmol} / 1 \text { (fasting plasma glucose } \geq 7 \\
\mathrm{mmol} / \mathrm{l} \text { ) and } / \text { or } 2 \mathrm{~h} \mathrm{blood} \text { glucose } \geq 9.0 \mathrm{mmol} / 1 \\
\text { (plasma glucose } \geq 10 \mathrm{mmol} / \mathrm{l} \text { ) }\end{array}$ & $\begin{array}{l}\text { Inpatient diagnosis or cause of death identifying ischaemic } \\
\text { heart disease, ischaemic stroke, atherosclerosis, } \\
\text { peripheral vascular disease }\end{array}$ \\
\hline Savitz et al [17] & 2014 & ICD (9th revision) ${ }^{\mathrm{a}}$ codes for gestational diabetes & $\begin{array}{l}\text { Heart failure, intracranial haemorrhage, stroke/TIA, } \\
\text { coronary heart disease }\end{array}$ \\
\hline Kaul et al [18] & 2015 & $\begin{array}{l}\text { Canadian Diabetes Association guidelines: } 50 \mathrm{~g} \text { glucose } \\
\text { challenge followed by } 75 \text { or } 100 \mathrm{~g} \text { glucose challenge }\end{array}$ & $\begin{array}{l}\text { One inpatient hospitalisation or two outpatient visits in } \\
2 \text { years for CVD (ischaemic heart disease and } \\
\text { cerebrovascular disease) }\end{array}$ \\
\hline Goueslard et al [8] & 2016 & ICD $(10 \text { th revision })^{\mathrm{b}}$ codes for gestational diabetes & $\begin{array}{l}\text { Angina, myocardial infarction, ischaemic stroke, TIA, } \\
\text { cerebrovascular disease }\end{array}$ \\
\hline Tobias et al [6] & 2017 & Self-report of physician's diagnosis & Non-fatal and fatal myocardial infarction and stroke \\
\hline $\begin{array}{l}\text { Retnakaran and Shah } \\
\text { [9] }\end{array}$ & 2017 & Physician diagnosis (administrative codes) & $\begin{array}{l}\text { Hospitalisation for myocardial infarction, acute coronary } \\
\text { syndrome, coronary artery bypass graft, percutaneous } \\
\text { coronary intervention, stroke, or carotid endarterectomy }\end{array}$ \\
\hline Daly et al [19] & 2018 & Physician diagnosis (administrative codes) & $\begin{array}{l}\text { Clinical diagnosis of coronary artery disease (ischaemic } \\
\text { heart disease) and cerebrovascular disease (stroke or TIA) }\end{array}$ \\
\hline $\begin{array}{l}\text { McKenzie-Sampson } \\
\text { et al [20] }\end{array}$ & 2018 & ICD $(10 \text { th revision })^{\mathrm{b}}$ codes for gestational diabetes & Hospitalisation for cardiovascular outcomes and procedures \\
\hline
\end{tabular}

${ }^{a}$ ICD-9 codes are available at www.icd9data.com/2007/Volume1

${ }^{\mathrm{b}}$ ICD-10 codes are available at http://apps.who.int/classifications/icd10/browse/2016/en

$\mathrm{CHF}$, congestive heart failure; TIA, transient ischaemic attack

youth at presentation in pregnancy, the risk of CVD in women with GDM is evident by as early as the first decade after delivery. Thus, the diagnosis of GDM provides a unique opportunity to identify future risk of vascular disease in young women at an early point in the disease's natural history, when risk modification and primary prevention may potentially be feasible.

Though sometimes under-recognised because of sexspecific differences in presentation, CVD remains the leading

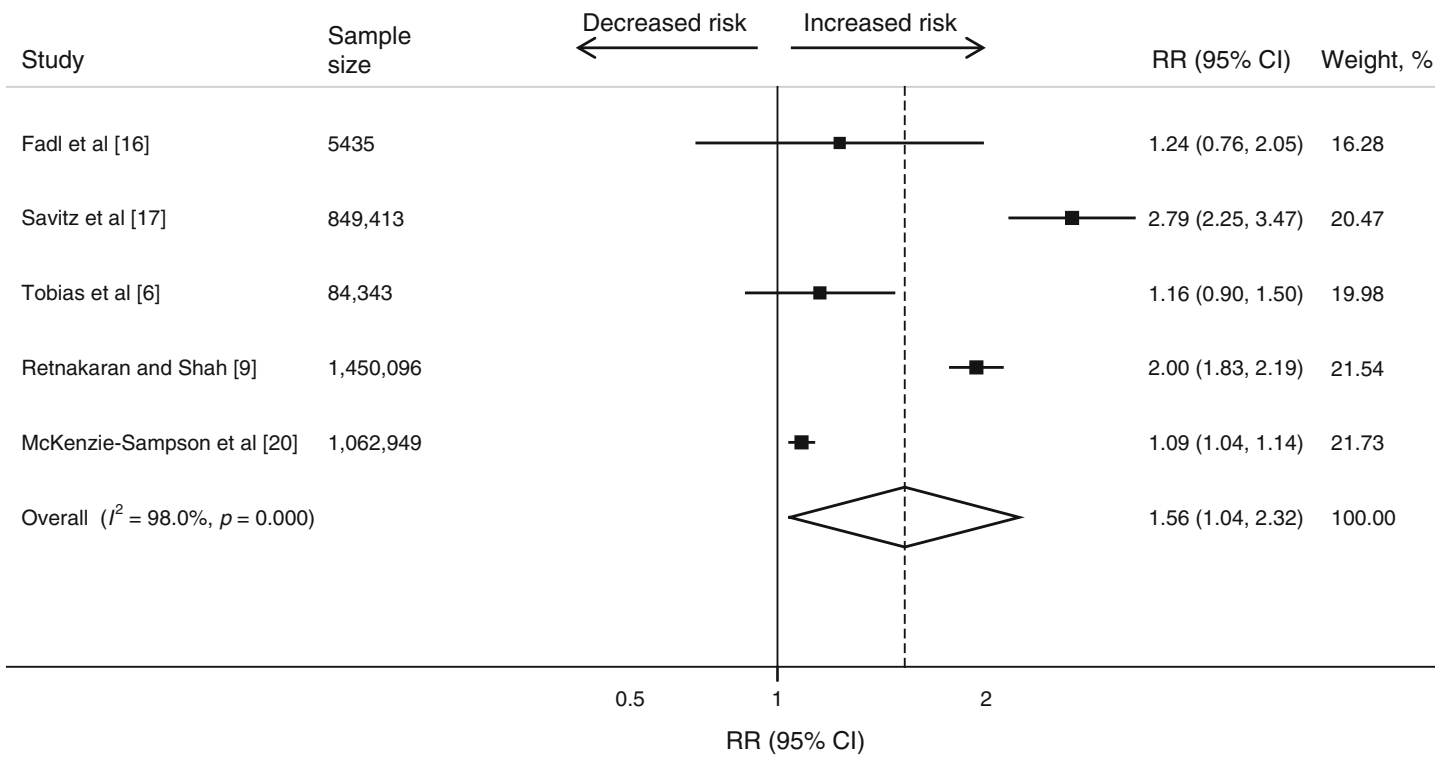

Fig. 2 Impact of type 2 diabetes on the relationship between GDM and cardiovascular events: meta-analysis of the association between GDM and the risk of cardiovascular events in women who did not develop type 2 diabetes. Weights are from random-effects analysis 


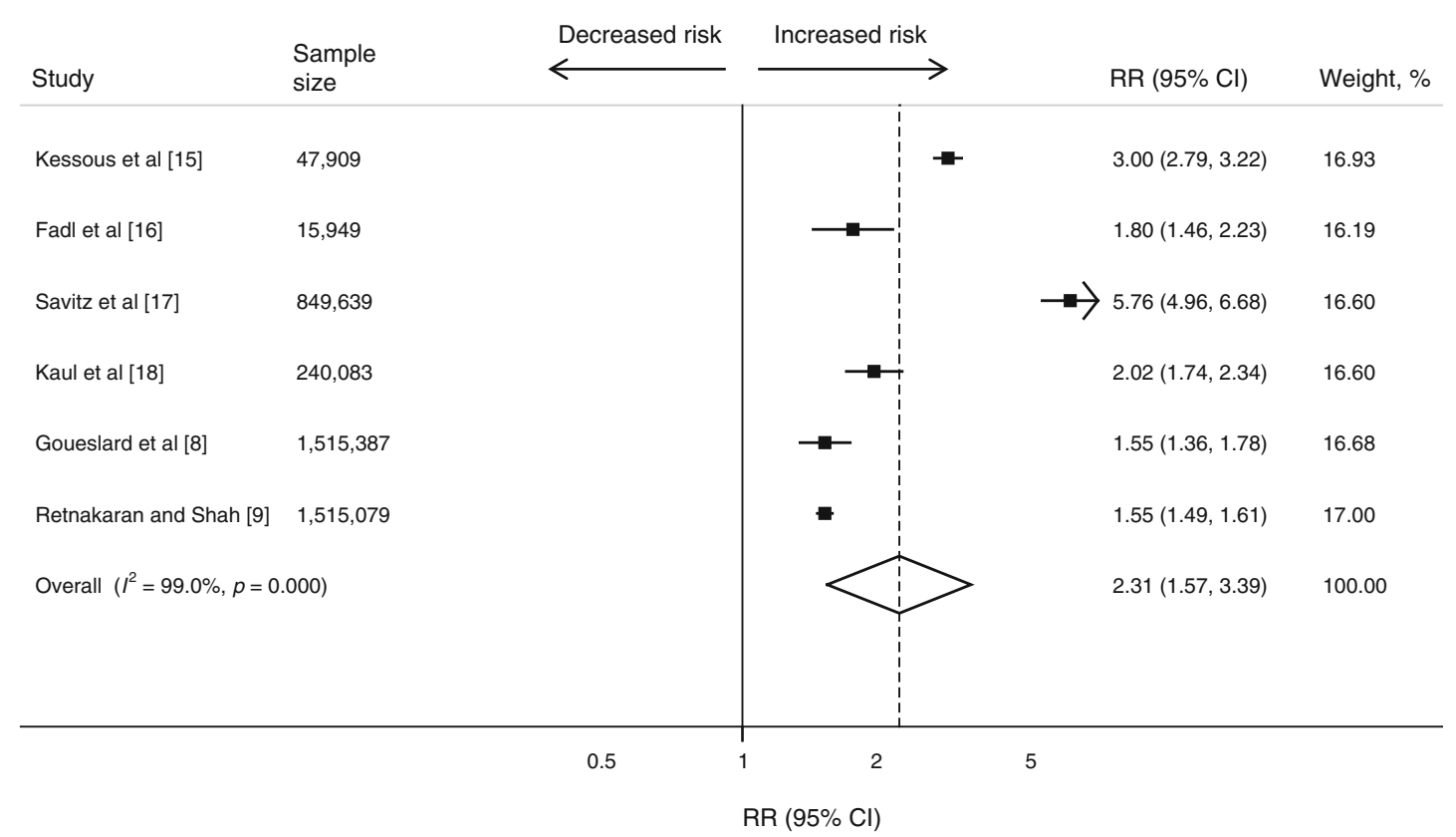

Fig. 3 Association between duration of follow-up and risk of cardiovascular events conferred by GDM: meta-analysis of the association between GDM and the risk of cardiovascular events in studies with $\leq 10$ years of follow-up. Weights are from random-effects analysis

cause of death in women $[21,22]$. In recent years, there has been growing recognition that adverse pregnancy outcomes (such as GDM, pre-eclampsia and pre-term delivery) can identify future cardiovascular risk in women, although clinical uptake of this concept has been limited [22]. In the case of GDM, three factors have likely contributed to this limited awareness: (1) the very recent emergence of the association of GDM with CVD (e.g. all the studies in this meta-analysis were published within the past 6 years); (2) the range of risk estimates that these studies have provided; and (3) uncertainty over whether the cardiovascular risk is entirely dependent upon type 2 diabetes. An earlier meta-analysis [23] included fewer studies and its risk estimate was compromised by the inclusion of two studies from our group that had overlapping participant populations [4, 9] and studies with self-reported outcomes [7, 24], as well as no assessment of the role of type 2 diabetes. The current meta-analysis was thus designed to address these gaps.

Our analysis reveals that, based on the studies to date, the elevated cardiovascular risk associated with previous GDM is relatively modest in its overall magnitude, in keeping with the low likelihood of major cardiovascular events in young women. Importantly, however, closer consideration of these data provides some revealing insights. First, it is notable that the association between GDM and CVD is consistently apparent across study populations of varying sizes from different countries (Table 1). Considering the lack of consensus in GDM diagnostic criteria and screening protocols across jurisdictions (and hence the anticipated clinical heterogeneity of the GDM groups across studies), this consistency is suggestive of a robust association between hyperglycaemia in pregnancy and subsequent CVD. Indeed, consistent with this concept, even women with mild glucose intolerance in pregnancy (not meeting the diagnostic criteria for GDM) have been shown to have an elevated risk of cardiovascular events over a median of 12.3 years after delivery as compared with their normoglycaemic peers [5].

The second key point is that the increased risk of CVD following GDM is already apparent within the first decade after the pregnancy, at a time in life when women would be otherwise unlikely to experience major cardiovascular events. Coupled with the observation that the differential risk between women with previous GDM and their peers appears to decline over time (likely reflecting the increased incidence of CVD overall in women after their reproductive years), these data suggest that the diagnosis of GDM identifies a high-risk vascular phenotype prior to its clinical presentation. Accordingly, the GDM-CVD association can be viewed as a unique opportunity for the early identification of impending vascular risk in a population of young women in whom it may not have been previously suspected, thereby raising the possibility of risk modification and primary prevention.

In this context, our demonstration that this risk is not entirely dependent upon the development of type 2 diabetes holds implications for practice. Specifically, our data show that, even if they do not progress to type 2 diabetes, women with GDM have an elevated risk of CVD. Moreover, the same message is conveyed by the early divergence of cardiovascular risk between women with and without GDM within the first decade after pregnancy, insofar as that modest window likely provides insufficient time for postpartum progression to type 2 diabetes to be solely responsible for the atherosclerotic process underlying CVD. While we cannot exclude the 
possibility that the pathologic processes underlying type 2 diabetes and CVD may evolve over time in parallel with one another (as per the "common soil" hypothesis) [25], the practice point emerging from these data is that, regardless of whether they have developed type 2 diabetes, women with a history of GDM have a higher risk of CVD than their peers and hence warrant an enhanced index of suspicion in this regard.

Since type 2 diabetes is not the sole determinant of the increased CVD risk, it is reasonable to consider the status of other cardiovascular risk factors in this population. In this context, it is notable that, compared with their peers, women with a history of GDM have a higher prevalence of several cardiovascular risk factors, including the metabolic syndrome, hypertension, elevated C-reactive protein, hypoadiponectinemia and dyslipidaemia (including low levels of HDL-cholesterol and elevated triacylglycerols, LDL-cholesterol, apolipoprotein-B, and small dense LDL particles) [26-28]. In addition, each of these features has been shown to be present as early as 3 months after delivery, suggesting that women with GDM may experience long-term exposure to this enhanced risk factor profile [3, 26-28]. Further supporting this chronicity is a growing body of evidence showing that women who develop GDM have cardiometabolic abnormalities prior to their pregnancy $[29,30]$. Taken together, these data support the emerging concept that women who develop GDM actually have a chronic metabolic disorder that comes to clinical attention during gestation, although it exists before, during and after the pregnancy [30]. In this way, the diagnosis of GDM may be seen as identifying women who have a longstanding, high-risk cardiometabolic phenotype that would otherwise escape clinical detection during the relative youth of their childbearing years, if not for the glucose tolerance screening that they undergo in pregnancy (which is the only situation in practice in which population testing for diabetes is routinely performed). Accordingly, it may be that long-standing exposure to this risk factor profile ultimately contributes to the risk of CVD and its manifestation earlier in life in women with GDM, as compared with their peers.

It should be appreciated that there may be unrecognised factors both during and after pregnancy that contribute to the observed association of GDM and subsequent CVD. These could include associated conditions in pregnancy (e.g. pre-eclampsia) or latent unrecognised cardiovascular risk determinants. The importance of further research to elucidate these factors is underscored by the fact that their recognition could inform future practice strategies for identifying those women with GDM who are at highest risk for CVD.

A strength of this study is the large sample size, with data from a variety of countries (Canada, USA, UK, France, Sweden and Israel), reflecting a range of ethnic groups. Indeed, the Canadian cohort studies $[9,18,20]$ were performed using population-based provincial databases that reflect the multi-ethnic compositions of their respective provinces. Accordingly, the current data provide a robust estimate of the risk of CVD following GDM that should be widely generalisable. Conversely, a limitation is that there were only nine studies and there was some heterogeneity in effect size. Although there was no evidence of publication bias in our analyses, it is also still possible that there could be small unpublished negative studies. In addition, the absence of data on cardiovascular risk factors in the studies included in this analysis precluded the direct evaluation of their impact. Future studies should therefore include longitudinal characterisation over time of cardiovascular risk factors and vascular function in women with recent GDM. The over-arching objective of such research would be to identify the relevant risk determinants and then ideally to intervene upon them prior to the development of abnormal vascular function and structure. In this regard, it is encouraging that studies to date have yielded conflicting findings on whether women with recent GDM have impaired endothelial function in the early postpartum years [3], suggesting that a window of opportunity for intervention may still be open at that point in time. While the ultimate clinical goal would be for practitioners to use the insight into future cardiovascular risk provided by the diagnosis of GDM to intervene and prevent the development of vascular disease in women, the indispensable first step towards this objective is widespread clinical awareness of the GDMCVD association, particularly in young women of reproductive age in whom practitioners may not otherwise suspect underlying vascular disease.

In conclusion, the diagnosis of GDM identifies young women who have a twofold elevated risk of developing CVD in the years thereafter, as compared with their peers. This risk is not dependent upon the intercurrent development of type 2 diabetes and is apparent as early as the first decade after pregnancy. Thus, the diagnosis of GDM should be recognised as providing a unique window into a woman's future risk of CVD, and hence an opportunity for early risk modification and possibly prevention of the leading cause of mortality in women.

Acknowledgements CKK holds a Canadian Diabetes Association Clinician-Scientist award. RR holds the Boehringer Ingelheim Chair in Beta-cell Preservation, Function and Regeneration at Mount Sinai Hospital, and his research programme is supported by the Sun Life Financial Program to Prevent Diabetes in Women.

Data availability Data may be obtained from the corresponding author upon request.

Funding This research received no specific grant from any funding agency in the public, commercial or not-for-profit sectors.

Duality of interest CKK has received grants from Boehringer Ingelheim, outside the submitted work. SC has nothing to disclose. RR has received grants and personal fees from Novo Nordisk, grants from Boehringer Ingelheim, personal fees from Eli Lilly, personal fees from Takeda, personal fees from Sanofi, and grants and personal fees from Merck, outside the submitted work. 
Contribution statement $\mathrm{CKK}$ and RR conceived the systematic review and analysis plan. CKK and SC selected studies for inclusion and abstracted data. CKK performed the statistical analyses. CKK and RR interpreted the data. All authors wrote the first draft, critically revised the manuscript for important intellectual content and approved the final draft. RR is guarantor of this work.

Publisher's note Springer Nature remains neutral with regard to jurisdictional claims in published maps and institutional affiliations.

\section{References}

1. O'Sullivan JB, Mahan CM (1964) Criteria for the oral glucose tolerance test in pregnancy. Diabetes 13:278-285

2. Bellamy L, Casas JP, Hingorani AD, Williams D (2009) Type 2 diabetes after gestational diabetes a systematic review and metaanalysis. Lancet 373(9677):1773-1779. https://doi.org/10.1016/ S0140-6736(09)60731-5

3. Retnakaran R (2018) Hyperglycemia in pregnancy and its implications for a woman's future risk of cardiovascular disease. Diabetes Res Clin Pract 145:193-199. https://doi.org/10.1016/j.diabres. 2018.04.008

4. Shah BR, Retnakaran R, Booth GL (2008) Increased risk of cardiovascular disease in young women following gestational diabetes. Diabetes Care 31(8):1668-1669. https://doi.org/10.2337/dc080706

5. Retnakaran R, Shah BR (2009) Mild glucose intolerance in pregnancy and risk of cardiovascular disease in young women: population-based cohort study. CMAJ 181(6-7):371-376. https:// doi.org/10.1503/cmaj.090569

6. Tobias DK, Stuart JJ, Li S et al (2017) Association of history of gestational diabetes with long-term cardiovascular disease risk in a large prospective cohort of US women. JAMA Intern Med 177(12): 1735-1742. https://doi.org/10.1001/jamainternmed.2017.2790

7. Carr DB, Utzschneider KM, Hull RL et al (2006) Gestational diabetes mellitus increases the risk of cardiovascular disease in women with a family history of type 2 diabetes. Diabetes Care 29(9):2078 2083. https://doi.org/10.2337/dc05-2482

8. Goueslard K, Cottenet J, Mariet AS et al (2016) Early cardiovascular events in women with a history of gestational diabetes mellitus. Cardiovasc Diabetol 15(1):15. https://doi.org/10.1186/s12933-0160338-0

9. Retnakaran R, Shah BR (2017) Role of type 2 diabetes in determining retinal, renal and cardiovascular outcomes in women with previous gestational diabetes. Diabetes Care 40(1):101-108. https:// doi.org/10.2337/dc16-1400

10. Stroup DF, Berlin JA, Morton SC et al (2000) Meta-analysis of observational studies in epidemiology: a proposal for reporting. Meta-analysis of Observational Studies in Epidemiology (MOOSE) group. JAMA 283(15):2008-2012. https://doi.org/10. 1001/jama.283.15.2008

11. Wells GA, Shea B, O'Connell D et al The Newcastle-Ottawa Scale (NOS) for assessing the quality of nonrandomised studies in metaanalyses. Available from http://www.ohri.ca/programs/clinical_ epidemiology/oxford.asp. Accessed 10 Feb 2019

12. Stang A (2010) Critical evaluation of the Newcastle-Ottawa scale for the assessment of the quality of nonrandomized studies in metaanalyses. Eur J Epidemiol 25(9):603-605. https://doi.org/10.1007/ s10654-010-9491-z

13. Higgins JP, Thompson SG (2002) Quantifying heterogeneity in a meta-analysis. Stat Med 21(11):1539-1558. https://doi.org/10. 1002/sim.1186
14. Begg CB, Mazumdar M (1994) Operating characteristics of a rank correlation test for publication bias. Biometrics 50(4):1088-1101. https://doi.org/10.2307/2533446

15. Kessous R, Shoham-Vardi I, Pariente G, Sherf M, Sheiner E (2013) An association between gestational diabetes mellitus and long-term maternal cardiovascular morbidity. Heart 99(15):1118-1121. https://doi.org/10.1136/heartjnl-2013-303945

16. Fadl H, Magnuson A, Östlund I, Montgomery S, Hanson U, Schwarcz E (2014) Gestational diabetes mellitus and later cardiovascular disease: a Swedish population based case-control study. BJOG 121(12):1530-1536. https://doi.org/10.1111/1471-0528. 12754

17. Savitz DA, Danilack VA, Elston B, Lipkind HS (2014) Pregnancyinduced hypertension and diabetes and the risk of cardiovascular disease, stroke, and diabetes hospitalization in the year following delivery. Am J Epidemiol 180(1):41-44. https://doi.org/10.1093/ aje/kwu118

18. Kaul P, Savu A, Nerenberg KA et al (2015) Impact of gestational diabetes mellitus and high maternal weight on the development of diabetes, hypertension and cardiovascular disease: a populationlevel analysis. Diabet Med 32(2):164-173. https://doi.org/10. 1111/dme.12635

19. Daly B, Toulis KA, Thomas N et al (2018) Increased risk of ischemic heart disease, hypertension, and type 2 diabetes in women with previous gestational diabetes mellitus, a target group in general practice for preventive interventions: a population-based cohort study. PLoS Med 15(1):e1002488. https://doi.org/10.1371/journal. pmed. 1002488

20. McKenzie-Sampson S, Paradis G, Healy-Profitós J, St-Pierre F, Auger N (2018) Gestational diabetes and risk of cardiovascular disease up to 25 years after pregnancy: a retrospective cohort study. Acta Diabetol 55(4):315-322. https://doi.org/10.1007/s00592-0171099-2

21. Mozaffarian D, Benjamin EJ, Go AS et al (2015) Heart disease and stroke statistics - 2015 update: a report from the American Heart Association. Circulation 131(4):e29-e322. https://doi.org/10.1161/ CIR.0000000000000152

22. Hauspurg A, Ying W, Hubel CA, Michos ED, Ouyang P (2018) Adverse pregnancy outcomes and future maternal cardiovascular disease. Clin Cardiol 41(2):239-246. https://doi.org/10.1002/clc. 22887

23. Li J, Song C, Li C, Liu P, Sun Z, Yang X (2018) Increased risk of cardiovascular disease in women with prior gestational diabetes: a systematic review and meta-analysis. Diabetes Res Clin Pract 140: 324-338. https://doi.org/10.1016/j.diabres.2018.03.054

24. Shostrom DCV, Sun Y, Oleson JJ, Snetselaar LG, Bao W (2017) History of gestational diabetes mellitus in relation to cardiovascular disease and cardiovascular risk factors in US women. Front Endocrinol 8:144. https://doi.org/10.3389/fendo.2017.00144

25. Stern MP (1995) Diabetes and cardiovascular disease: the "common soil" hypothesis. Diabetes 44(4):369-374. https://doi.org/10. 2337/diab.44.4.369

26. Retnakaran R, Qi Y, Sermer M, Connelly PW, Zinman B, Hanley $\mathrm{AJ}$ (2010) Glucose intolerance in pregnancy and postpartum risk of metabolic syndrome in young women. J Clin Endocrinol Metab 95(2):670-677. https://doi.org/10.1210/jc.2009-1990

27. Retnakaran R, Qi Y, Connelly PW, Sermer M, Hanley AJ, Zinman B (2010) Low adiponectin concentration during pregnancy predicts postpartum insulin resistance, beta-cell dysfunction and fasting glycaemia. Diabetologia 53(2):268-276. https://doi.org/10.1007/ s00125-009-1600-8

28. Retnakaran R, Qi Y, Connelly PW, Sermer M, Hanley AJ, Zinman B (2010) The graded relationship between glucose tolerance status in pregnancy and postpartum levels of LDL cholesterol and apolipoprotein B in young women: implications for future 
cardiovascular risk. J Clin Endocrinol Metab 95(9):4345-4453. https://doi.org/10.1210/jc.2010-0361

29. Harville EW, Viikari JS, Raitakari OT (2011) Preconception cardiovascular risk factors and pregnancy outcome. Epidemiology 22(5): 724-730. https://doi.org/10.1097/EDE.0b013e318225c960
30. Retnakaran R (2016) The insulin-like growth factor axis: a new player in gestational diabetes? Diabetes 65(11):3246-3248. https://doi.org/10.2337/dbi16-0048 